\title{
Role of GnRH in the ontogeny and regulation of the fetal hypothalamo-pituitary-gonadal axis in sheep
}

\author{
A. N. Brooks ${ }^{1}$, A. S. McNeilly ${ }^{1}$ and G. B. Thomas ${ }^{2}$ \\ ${ }^{1}$ MRC Reproductive Biology Unit, Centre for Reproductive Biology, 37 Chalmers Street, \\ Edinburgh, EH3 9EW, UK, and ${ }^{2}$ Division of Neurophysiology and Neuropharmacology, National \\ Institute for Medical Research. The Ridgeway, Mill Hill, London NW7 IAA, UK
}

Adult reproductive ability is to a large extent determined by the appropriate development of the reproductive axis during fetal life. Studies have investigated the role of the fetal hypothalamus in the ontogeny and regulation of pituitary gonadal function during fetal development in sheep. Using immunocytochemistry, we examined the ontogeny of gonadotroph development in the pituitary of female sheep fetuses. At day 70 of gestation (term $=145$ days), only immunopositive LH $\beta$ cells were present. The number and intensity of staining of these LH $\beta$ cells had increased by day 100 but had declined again by day 130. Immunopositive $\alpha$-subunit and FSH $\beta$ cells appeared at day 100 of gestation and had further increased in number and staining intensity by day 130 of gestation. Treatment of fetuses with the GnRH agonist buserelin resulted in desensitization of the fetal pituitary gonadotrophs, inhibition of pituitary LH $\beta$ and FSH $\beta$ mRNA expression and a reduction in the number of immunopositive gonadotrophin-containing cells. Pulsatile GnRH treatment resulted in pituitary-gonadal activation and an increase in LH, FSH and testosterone secretion in males. Thus, the synthesis and secretion of the gonadotrophins during fetal development is critically dependent on the secretion of $\mathrm{GnRH}$ from the fetal hypothalamus. Inhibition of fetal gonadotrophins by buserelin treatment from day 70 of gestation resulted in a $40 \%$ reduction in the size of the fetal testis at birth, and there were no effects on the fetal ovaries. This reduction in testis size was due to a $45 \%$ reduction in the number of Sertoli cells. However, when buserelin was given between day 70 and day 110 of gestation, there were no effects on testis size or morphological development of the testis, suggesting that gonadotrophins regulate testicular development during a 'critical window' late in gestation. Taken together, these studies provide convincing evidence that $\mathrm{GnRH}$ plays a central role in the ontogeny and regulation of pituitary-gonadal function during fetal life.

\section{Introduction}

During fetal development, the hypothalamo-pituitary-gonadal axis undergoes a series of unique maturational and functional changes. The fetal pituitary-gonadal axis is extremely active during development and activity reaches a peak at mid-gestation; this is followed by a period of suppression which persists until the onset of puberty. A number of studies have described changes in plasma gonadotrophin concentrations during fetal development in sheep (Foster et al., 1972; Alexander ef al., 1973; Sklar et al, 1981). The current view is that plasma LH and FSH concentrations are higher at mid-gestation than during early gestation and immediately before birth. Furthermore, at mid-gestation 
there is a sex difference in fetal gonadotrophin concentrations: LH and FSH are lower in males than in female fetuses. This difference is believed to result from the negative feedback effects of testosterone present in the circulation of male fetuses (Sklar et al, 1981; see below). This view of the pattern of change in LH and FSH is primarily based on studies using a cross-sectional approach in which single blood samples were collected by cardiac puncture under anaesthesia. This approach is not ideal as gonadotrophins (particularly LH) are secreted in a pulsatile fashion which may be affected by anaesthesia. Unfortunately, because of technical difficulties associated with maintaining patent catheters in fetal sheep for protracted periods, there are no longitudinal studies that chart the normal ontogeny of circulating gonadotrophin concentrations in fetuses. However, Phillips of al. (1992) measured changes in FSH in samples collected by cardiac puncture in a uniform fashion at specific times during gestation. This improved experimental approach demonstrates a pattern of change in FSH that is broadly similar to the results previously obtained, except for a sex difference in FSH secretion during late gestation (females having higher FSH concentrations than males) which was not revealed in the earlier studies. Frequent collection of blood samples from catheterized sheep fetuses has shown that LH is secreted in a pulsatile fashion, although the ontogeny of LH pulse characteristics such as frequency and amplitude are not clear (Clark et al., 1984; Matwijiw and Faiman, 1989; Albers et al., 1993). However, there is one report that describes a significant decline in the frequency of LH pulses in male and female fetuses after day 130 of gestation compared with fetuses sampled before day 130 (Mesiano et al, 1991), which is consistent with the previously reported decline in mean $\mathrm{LH}$ concentrations before birth (term $=145$ days in sheep). This review will discuss the ontogeny, regulation and function of the pituitary-gonadal axis in sheep with particular reference to the role of $\mathrm{GnRH}$ in these processes.

\section{Ontogeny of Gonadotroph Development in the Fetal Pituitary Gland}

The differentiation and development of the gonadotrophs in the fetal pituitary gland are necessary prerequisites for a functional hypothalamo-hypophysial axis during fetal life and are poorly understood. We examined the ontogeny of pituitary gonadotroph development in anterior pituitary glands collected from female sheep at days 70, 100 and 130 of gestation (Thomas ef al., 1993). Cells containing the common $\alpha$-subunit and the specific $\beta$-subunits of LH and FSH were localized by immunohistochemistry using the avidin-biotin immunoperoxidase technique. Common $\alpha$-subunit immunostaining was first detected in only $0.6 \%$ of cells at day 70 of gestation, but increased progressively in number and staining intensity to reach a maximum at day 130 (Fig. 1). FSH $\beta$ cells could not be detected at day 70 , but by day 100 of gestation, $5 \%$ of the cells of the anterior pituitary gland were immunopositive for FSH $\beta$. This number further increased to $8 \%$ by day 130 . In contrast, $2.1 \%$ of cells were immunopositive for LH at day 70 of gestation. The number $(15.6 \%)$ and staining intensity increased significantly by day 100 of gestation, but had declined to $8.7 \%$ by day 130 . These temporal changes in the number of immunopositive LH and FSH cells are in broad agreement with the reported changes in plasma concentrations of these hormones. In the sheep fetus the rise in the plasma concentrations of LH and FSH at mid-gestation coincides with the increase in numbers and staining intensity of gonadotrophs localized in the anterior pituitary gland in our own study. It also coincides with a reported increase in the number of heterogeneous gonadotrophs containing both LH and FSH in the pituitary gland of the sheep fetus (Hadj et al., 1993). The subsequent decline in LH secretion which is accompanied by a decline in the frequency of $\mathrm{LH}$ pulses is paralleled by a decline in the number of $\mathrm{LH}$ immunopositive cells and may be due to the maturation of steroid feedback mechanisms at this time (see below). The increase in the number of FSH containing cells at late gestation is not in agreement with the reported changes in FSH concentrations in the fetal circulation. However, these changes in FSH secretion during fetal development are likely to be an inaccurate reflection of synthesis and storage within the pituitary gland. Phillips et al. (1992) showed that pituitary contents and concentrations of bioactive and immunoreactive FSH were higher in females than in males, but increased in both sexes between day 75 and day 135 of gestation. Plasma concentrations of bioactive FSH remained constant from day 75 onwards, whereas immunoreactive concentrations declined at term. Thus, the ontogenic pattern of FSH content in the fetal pituitary gland and bioactive FSH in the circulation shows close correlation with the increase in the 


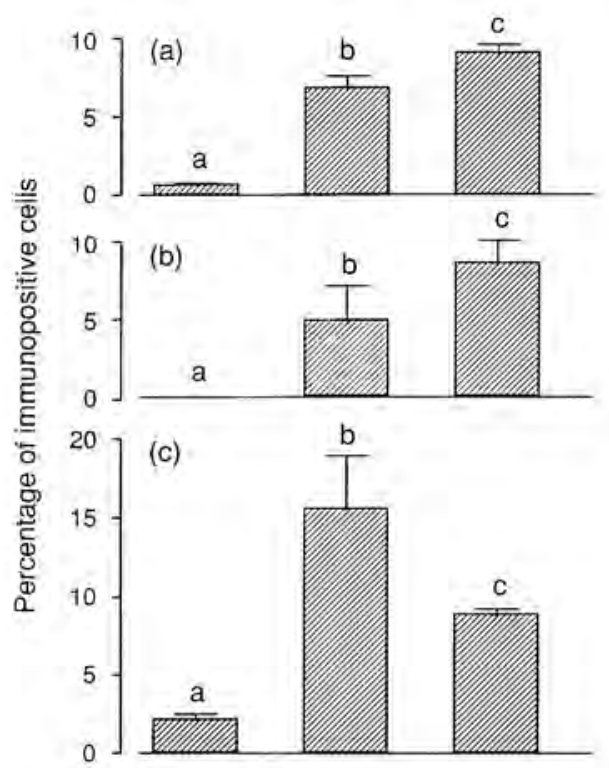

(d)

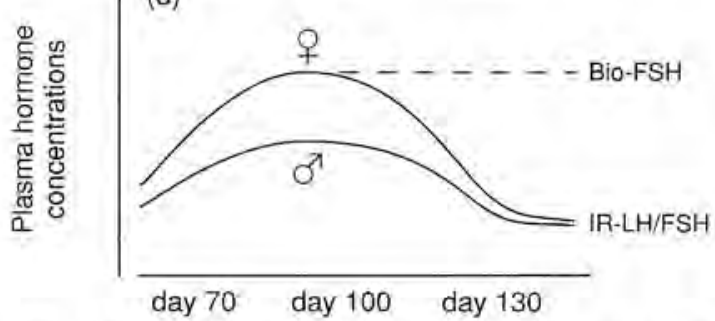

Fig. 1. Percentage of cells containing immunopositive (a) common $\alpha$-subunit, (b) LH $\beta$ and (c) FSH $\beta$ in the anterior pituitary gland of sheep fetuses and comparison with (d) a schematic representation of fetal plasma gonadotrophin concentrations. Groups with different letters are significantly different, (Redrawn from Thomas et al., 1993.)

numbers of gonadotrophs containing FSH observed in our own study. The mechanisms regulating the preferential release of bioactive FSH during late gestation remain to be determined.

The absence of significant numbers of cells containing common $\alpha$-subunit at day 70 of gestation is in conflict with the current view that the $\alpha$-subunit gene is the earliest hormone gene to be expressed in the developing pituitary gland. For instance in rats, in situ hybridization analysis has shown the presence of $\alpha$-subunit on embryonic day II, before the formation of the definitive Rathke's pouch which ultimately forms the anterior pituitary gland (Simmons et al, 1990). Specific LH- and FSH-containing cells do not appear until around embryonic day 17 . In humans, cells containing a-subunit have been detected by immunohistochemistry 3 weeks before the first appearance of LH and FSH cells at week 12 of gestation (Asa et al, 1986). The reason for the lack of $\alpha$-subunit staining is not clear but the simplest explanation is a species difference in the ontogeny of gonadotroph differentiation. However, in preliminary studies we found a small but significant amount of $\alpha$-subunit in the pituitary gland at day 70 of gestation when measured by radioimmunoassay in pituitary extracts (F. Gibson, A. S. McNeilly and A. N. Brooks, unpublished). These concentrations increase progressively during fetal development and parallel the increasing numbers of $\alpha$-subunit immunopositive cells detected by immunohistochemistry. Thus it is likely that the immunohistochemical technique simply lacks the sensitivity to detect the low amounts of $\alpha$-subunit at day 70 of gestation. Moreover, the small amount of $\alpha$-subunit produced at 
this early stage of gestation may immediately be associated with a corresponding $\beta$-subunit to yield intact glycoprotein hormone, or may be constitutively secreted without being stored in the pituitary gland.

\section{Hypothalamic Regulation of Fetal Gonadotrophins}

In adults, it is well established that the synthesis and secretion of pituitary gonadotrophins depend on the pattern of GnRH secretion into the hypophysial-portal vasculature. In the sheep fetus, the hypophysial-portal vasculature has fully developed by day 45 , thus providing a functional link between the hypothalamus and the pituitary gland at an early stage in gestation (Levidiotis et al., 1989; Matwijiw et al., 1989). Shortly after this, GnRH neurones can be identified in the preoptic area of the fetal hypothalamus (Caldani et al., 1995), and by day 70 of gestation gonadotrophs containing LH are present in the anterior pituitary gland (Thomas et al, 1993). By day 84 (the earliest age examined) exogenous administration of GnRH to catheterized sheep fetuses increases plasma concentrations of LH and FSH (Mueller et al., 1981) and administration of a GnRH antagonist blocks episodic LH release (Matwijiw and Faiman, 1987). These data suggest that the high circulating gonadotrophin concentrations observed during fetal life are the result of the actions of GnRH on the fetal pituitary gland rather than simply a reflection of autonomous secretion.

To examine the role of $\mathrm{GnRH}$ in the development of the pituitary-gonadal axis further, we exploited the ability of long-term administration of a GnRH agonist to cause desensitization of the pituitary gonadotrophs and thus block the actions of endogenous $\mathrm{GnRH}$ on the pituitary gland (Brooks and $\mathrm{McNeilly,} \mathrm{1992).} \mathrm{Sheep} \mathrm{fetuses} \mathrm{at} \mathrm{day} 70$ of gestation were treated with a subcutaneous biodegradable implant containing either 1.5 or $3.0 \mathrm{mg}$ of the long-acting GnRH agonist, buserelin [D-Ser(tBu) ${ }^{6}$, Pro $\left.{ }^{9}-\mathrm{NHEt}\right] \mathrm{GnRH}_{1-9}$. The ability of buserelin to cause desensitization of the fetal gonadotrophs was examined at day 110 of gestation, a time of high fetal gonadotrophic activity, and also in newborn lambs. For the fetal studies, catheters were inserted under general anaesthesia at day 105 of gestation and a 5 day recovery period was allowed before experiments commenced. Beginning at day 110 of gestation, blood samples were collected at intervals of $15 \mathrm{~min}$ for $4 \mathrm{~h}$ to monitor episodic LH secretion. LH pulses were evident in control fetuses, but were completely abolished in fetuses pretreated with buserelin. Furthermore, mean plasma concentrations of LH and FSH were significantly suppressed by buserelin treatment. The efficacy of buserelin treatment was further investigated by measuring the gonadotrophin responses to bolus administration of exogenous $\mathrm{GnRH}$. In control fetuses, GnRH elicited a sharp increase in LH release, a response which was completely abolished in fetuses that were treated with buserelin. Similar findings were seen in newborn lambs that had received buserelin from day 70 of gestation (Thomas et al., 1994a). Thus, we concluded that long-term treatment of sheep fetuses with buserelin results in desensitization of fetal pituitary gonadotrophs and provides a useful model that can be used to inhibit fetal gonadotrophin secretion specifically throughout the second half of gestation.

We used this model to investigate whether $G_{n} R H$ is necessary for the synthesis of the specific gonadotrophin subunits in the developing anterior pituitary gland (Brooks et al., 1992). Sheep fetuses were treated with buserelin between day 70 and day 110 of gestation, at which time anterior pituitary glands were collected for measuring gonadotrophin subunits by specific radioimmunoassays and for extraction of total RNA followed by northern analysis using specific probes for LH $\beta$. FSH $\beta$ and the common $a$-subunit. Treatment with buserelin caused a highly significant reduction in the content of LH and FSH in anterior pituitary glands by $90-95 \%$ of control values and this was accompanied by a similar reduction in expression of mRNA encoding pituitary LH $\beta$ and FSH $\beta$ subunits (Fig. 2). Common $\alpha$-subunit content was extremely variable in control fetuses and was reduced by $70-80 \%$ after buserelin treatment. Common $\alpha$-subunit mRNA expression was also extremely variable in control animals and. although lower in fetuses treated with buserelin, this difference did not reach significance (Fig. 2).

The influence of buserelin on pituitary gonadotroph development was also investigated by immunohistochemistry in pituitaries collected from newborn lambs that had been treated with buserelin from day 70 of gestation (Thomas et al., 1994a). In control lambs there was intense immunostaining corresponding to $\alpha$-subunit, LH $\beta$ and FSH $\beta$, whereas pituitary glands from buserelin-treated fetuses had 


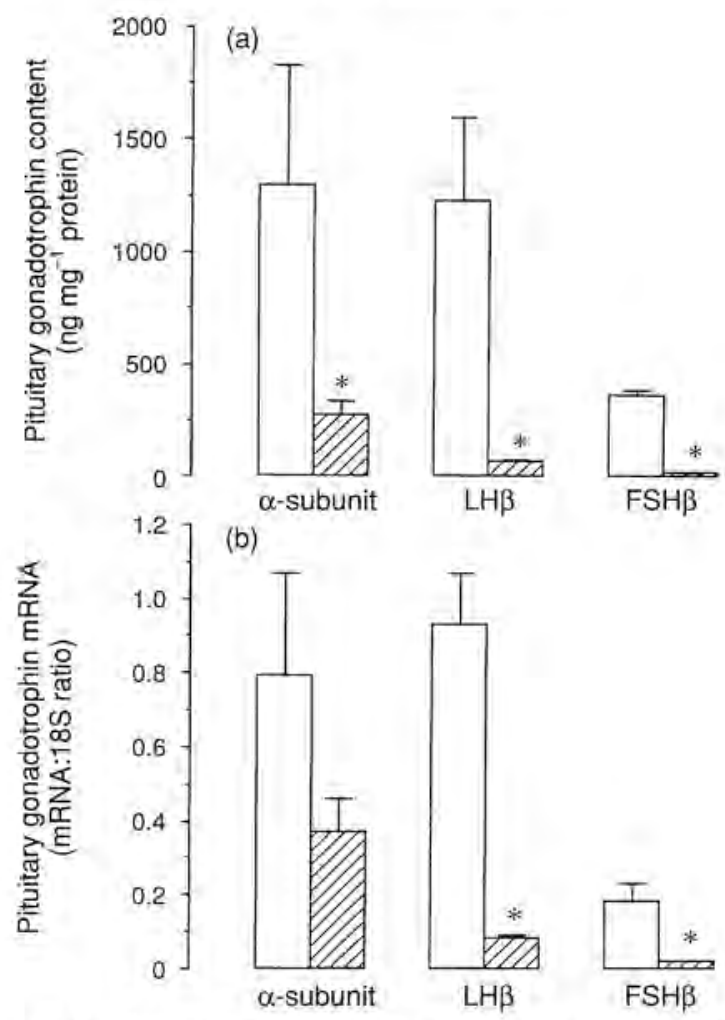

Fig. 2. Effects of buserelin administration between day 70 and day 110 of gestation on (a) pituitary gonadotrophin content and (b) pituitary gonadotrophin mRNA. All values are means \pm SEM of between 4 and 12 determinations. *Significant $(P<0.001$. ANOVA $)$ difference between control ( $\square$ ) and buserelin-treated (ZZ) fetuses. There was no effect of fetal sex on these data and so data for both sexes have been pooled.

no immunopositive LH or FSH cells. This was matched by a highly significant reduction in the pituitary content of LH and FSH measured by radioimmunoassay. In contrast, occasional faintly staining $\alpha$-subunit cells were still visible after buserelin treatment and pituitary $\alpha$-subunit content, although reduced, was not significantly different from controls (Thomas et al, 1994a).

Collectively, these results show that abolishing the action of GnRH on the fetal pituitary gland during the second half of gestation inhibits the synthesis and post-translational processing of LH and FSH. The regulation of $\alpha$-subunit does not appear to be exclusively dependent on the actions of $\mathrm{GnRH}$, but may instead be autonomous or regulated by factors in addition to $\mathrm{GnRH}$.

\section{Maturation of Inhibitory Mechanisms Resulting in Pituitary-Gonadal Suppression in Late Gestation}

The mid-gestation peak in pituitary-gonadal activity is followed by a period of low LH and FSH concentrations leading up to the time of birth and extending into the postnatal period until the onset of puberty (Sklar et al., 1981). The mechanisms responsible for this suppression are unclear but are thought to include maturation of sex-steroid feedback (including placental steroids) and increased central nervous system inhibition of GnRH secretion. 
Sex-steroid feedback

The fact that gonadotrophin concentrations are higher in female than in male fetuses suggests that the testis, but not the ovary, can exert negative feedback effects by mid-gestation. This concept is supported by data showing that castration of male but not female sheep fetuses at about day 110 of gestation results in a significant increase in LH pulse frequency and mean FSH concentrations (Matwijiw and Faiman, 1989, 1991; Mesiano et al., 1991). The fact that LH pulse frequency is higher in castrated males than in castrated females suggests that there is a sexually dimorphic GnRH pulse generator in this species. In rats, critically timed exposure of the developing hypothalamus to testosterone results in a permanent effect on the control of LH secretion and sexual behaviour in adults (reviewed by Gorski, 1985). In sheep, administration of testosterone to pregnant ewes between day 40 and day 86 of gestation causes female intact or castrated fetuses to exhibit a high frequency pattern of LH pulses that is typical of castrated male fetuses (Matwijiw and Faiman, 1991). Thus, testosterone has a major influence on the neural organization of the GnRH pulse generator, although the precise mechanisms involved are still poorly understood. The high frequency of LH pulses seen in castrated males at about day 110 of gestation declines significantly after day 130 of gestation to values similar to those seen in females and in intact males, suggesting that the effects of the testis are superseded by other factors late in gestation (Matwijiw and Faiman, 1989; Mesiano et al., 1991). The nature of these factors is unclear but it seems likely that the high concentrations of placentally derived oestrogens and progesterone present in the fetal circulation during late gestation will also exert negative feedback effects on the pituitary-gonadal axis.

An increase in sensitivity to oestradiol negative feedback in late gestation was reported by Gluckman et al, (1983). At day 90 of gestation infusion of oestradiol had no effect on basal circulating concentrations of LH and FSH. In contrast, at day 105 of gestation, oestradiol significantly inhibited basal LH and FSH secretion and reduced the LH, but not the FSH, response to GnRH pulses. These data suggest that the capacity for exogenous oestradiol administration to inhibit gonadotrophin secretion increases after day 90 of gestation and this maturation of negative feedback may account for the decline in plasma gonadotrophins late in gestation. However, there have been no studies using specific oestrogen antagonists to block endogenous oestrogen action, which would provide a clearer indication of whether oestrogens derived from the placenta are responsible for inhibiting the fetal pituitary gonadotrophs. A prerequisite for oestrogen action on gonadotrophin secretion is the presence of oestrogen receptors within the hypothalamo-hypophysial system. We have used immunocytochemistry to detect the presence of oestrogen receptors in the fetal pituitary gland. Oestrogen receptors are clearly visible in anterior pituitary glands of male and female fetuses by day 70 of gestation, at a time when LH immunopositive cells first appear (S. Cui, A. S. McNeilly and A. N. Brooks, unpublished). However, most of these receptors are confined to the cytoplasm and there is little immunostaining in the nucleus. By day 100 of gestation, there is a marked increase in the number of cells with oestrogen receptor immunostaining in the anterior pituitary gland, and an increase in the proportion of cells with nuclear staining. This increase in the number of oestrogen-receptor-positive cells occurs at the same time when oestrogen feedback matures, and provides further support for the important role of circulating oestrogens as negative feedback regulators of gonadotrophin secretion in fetal plasma.

Progesterone concentrations in fetal plasma are also high during late gestation (Challis et al, 1981) and could therefore inhibit gonadotrophin secretion as has clearly been demonstrated in adult sheep (see review by Martin, 1984). However, we previously reported that the progesterone receptor antagonist RU486 has no effect on circulating LH and FSH concentrations when given to castrated male and female fetuses after day 130 of gestation (Brooks et al., 1992). These data suggest that progesterone alone does not play a major role as a negative feedback modulator of fetal gonadotrophin secretion. However, it is possible that the overriding effects of oestradiol may mask any influence of progesterone. Further studies using combinations of oestrogen and progesterone antagonists are needed to unravel this complex issue.

\section{Central neroous system}

The decline in gonadotrophin concentrations at late gestation may result from an increase in inhibitory factors within the central nervous system which reduce the secretion of GnRH from the fetal hypothalamus. This has proved a difficult hypothesis to test because of the need to discriminate between 
influences of the central nervous system and the effects of other factors such as sex-steroid feedback (see above). Furthermore, the direct measurement of $\mathrm{GnRH}$ in pituitary-portal blood has not yet been accomplished in the fetus, so changes in LH concentrations in peripheral blood provide the only marker available for $\mathrm{GnRH}$ secretion. In adults there is generally a good correlation between $\mathrm{GnRH}$ pulses in the portal vasculature and LH pulses in the peripheral circulation, but this may not necessarily be the case during fetal development.

We have reasoned that if the decline in gonadotrophin secretion during late gestation is solely due to steroid feedback then stimulation of the fetal hypothalamus would elicit a progressively smaller release of $\mathrm{GnRH}$, and thus $\mathrm{LH}$, as gestation proceeds. We have therefore examined the ontogeny of $\mathrm{LH}$ responses to endogenously released $\mathrm{GnRH}$ by using a neuroactive amino acid analogue, $N$-methyl-Daspartate (NMDA) to stimulate the fetal hypothalamus. Catheterized sheep fetuses were treated on consecutive days with a bolus injection of saline vehicle, NMDA (4 mg kg ${ }^{-1}$ body mass) or GnRH ( $125 \mathrm{ng} \mathrm{kg}{ }^{-1}$ body mass) on three occasions, between days 110 and 115 , days 120 and 125 and days 135 and 140 of gestation. Intravenous bolus administration of NMDA significantly stimulated plasma LH concentrations at each of the gestational ages (Fig. 3a). The integrated LH response to NMDA was the same at days $110-115$ and days $120-12.5$ but increased significantly $(P<0.05$. ANOVA) by days 135-140 of gestation (Fig. 3b). At all gestational ages, GnRH elicited a greater release of LH than did NMDA, although the pattern of change through gestation was similar (Fig. 3b). Thus, stimulation of the central nervous system by activation of NMDA receptors causes an increase in LH secretion during late gestation. This finding and the fact that the $\mathrm{LH}$ response to $\mathrm{GnRH}$ also increases suggests that the development of sex-steroid feedback is not solely responsible for inhibiting gonadotrophin secretion.

\section{Can Pulsatile Administration of GnRH Re-activate Pituitary-Gonadal Function in Late Gestation?}

As GnRH and NMDA stimulate LH secretion during late gestation, we tested the hypothesis that repeated stimulation of the fetal pituitary with GnRH would result in sustained activation of fetal pituitary-gonadal function. Catheterized sheep fetuses between day 120 and day 134 of gestation (a time of low endogenous LH and FSH secretion) were treated with intravenous pulses of $500 \mathrm{ng}$ GnRH or saline administered as a bolus every $2 \mathrm{~h}$. Pituitary-gonadal responses were assessed by measuring plasma concentrations of $\mathrm{LH}, \mathrm{FSH}$, immunoreactive inhibin and testosterone in response to the first pulse of $\mathrm{GnRH}$ and to the corresponding pulse given on days $124,127,130$ and 134 of gestation. Within 5 min of injection each pulse of GnRH elicited a rapid rise in plasma $\mathrm{LH}$ concentrations. In males the LH released in response to $\mathrm{GnRH}$ caused a rise of testosterone into the fetal circulation within $40-60 \mathrm{~min}$. In contrast, FSH was not acutely released in response to $\mathrm{GnRH}$ administration. In male and female fetuses, the peak LH response to the first pulse of GnRH was significantly $(P<0.01$, ANOVA) greater than the responses thereafter (Table 1). In male fetuses, the peak testosterone response to the endogenously released LH was low after the first GnRH pulse but progressively increased throughout the treatment period (Table 1). The decline in the LH response to GnRH is intriguing and could result from downregulation of the $\mathrm{GnRH}$ receptor after continued pulsatile treatment. However, administration of GnRH pulses at intervals of $2 \mathrm{~h}$ was chosen on the basis of studies in adults which show that this is the frequency of administration that does not cause downregulation (McLeod and McNeilly, 1987). A more likely explanation is that the first $\mathrm{GnRH}$ pulse causes the secretion of a large readily releasable pool of LH from the pituitary gland which is not sufficiently replenished thereafter, with the result that subsequent LH pulses are of lower amplitude. The increase in testosterone secretion during the experiment could reflect an increasing sensitivity of the testis to LH or an increase in the bioactivity of LH released during the experiment. A similar phenomenon of upregulation has been observed in the fetal adrenal gland, in which ACTH sensitizes the adrenal gland to further ACTH stimulation by increasing ACTH binding and the functional coupling of the ACTH receptor to its second messenger systems (Challis and Brooks, 1989).

Although pulsatile $\mathrm{GnRH}$ administration did not elicit discrete bursts of FSH release, it did cause a marked increase in basal concentrations in both male and female fetuses throughout the experiment 

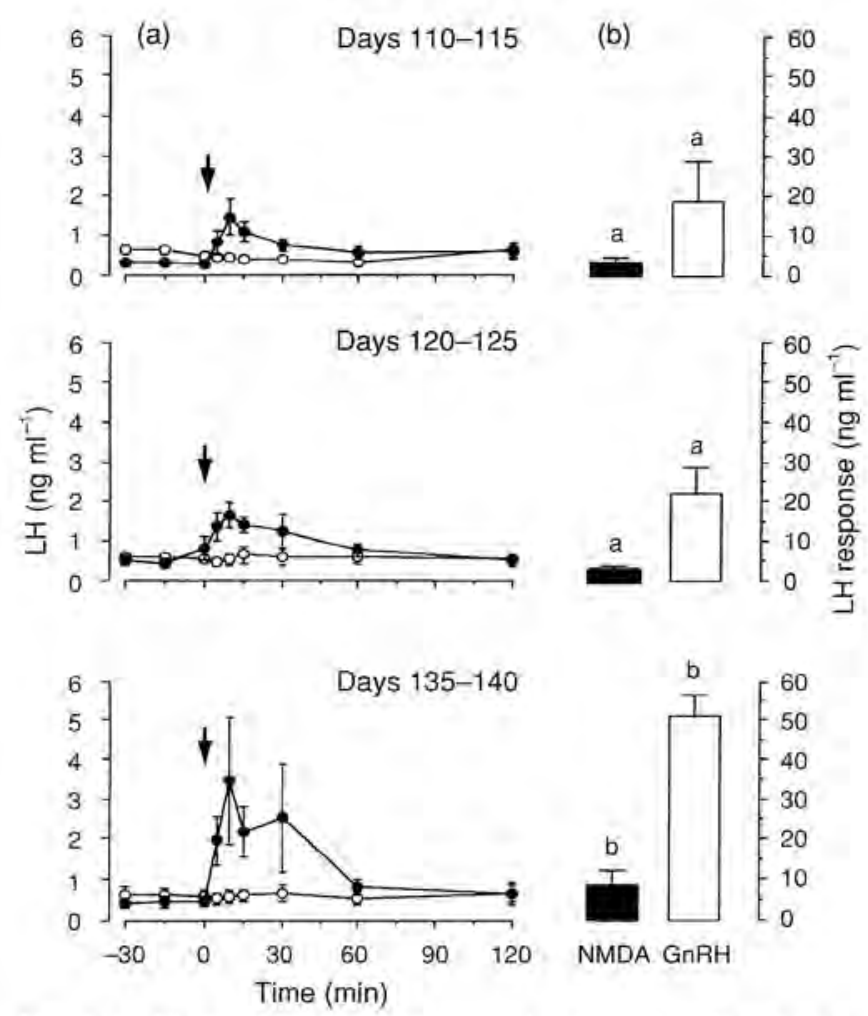

Fig. 3. (a) Effects of it. administration of saline ( $)$ ) or N-methyl-0aspartate (NMDA) ( ) on plasma concentrations of LH in catheterized sheep fetuses between days 110 and $115(n=5)$, days 120 and 125 $(n=5)$ and days 135 and $140(n=8)$. Each value represents the mean \pm SEM. The arrow indicates the time of injection. (b) Comparison of $\mathrm{LH}$ responses to i.v, administration of NMDA or GnRH to catheterized sheep fetuses. Values. (means \pm SEM) were calculated by summing the hormone concentrations taken after injection with average pretreatment values subtracted. Significant $(P<0.05$, ANOVA) differences between gestational ages are indicated by different letters.

(Table 2). Plasma concentrations of immunoreactive inhibin were higher in males than in females, and in males there was a progressive increase in immunoreactive inhibin concentrations throughout the experiment in both control and GnRH-treated fetuses (Table 2). This maturational change was not observed in female fetuses. The observation of a sex difference in immunoreactive inhibin concentrations accords with previous reports (Phillips et al, 1992) and suggests that the fetal testis, in contrast to the fetal ovary, actively synthesizes and secretes inhibin. We investigated the expression and localization of mRNA encoding inhibin $\alpha$ and $\beta A$-subunit and protein in fetal testis and ovaries by in situ hybridization and immunocytochemistry. In the fetal testis the expression of mRNA encoding inhibin $\alpha$-subunit increased progressively between day 70 and day 140 of gestation and was localized within the seminiferous cords (Thomas et al., 1994b; Fig. 4). Intense immunoreactivity was detected by day 100 of gestation and was clearly visible within the immature Sertoli cells and in a small proportion of Leydig cells. In the fetal ovary mRNA encoding inhibin $\alpha$-subunit was not detected until day 130-140 of gestation and was localized within a proportion (about 50\%) of secondary follicles and in all antral follicles (Engelhardt et al., in press). Faint positive immunostaining for inhibin $\alpha$-subunit was observed only in the antral follicles at days 130-140. At no time could we detect mRNA encoding $\beta A$ subunit or 
Table 1. $\mathrm{LH}$ and testosterone response to $500 \mathrm{ng} \mathrm{GnRH}$ injections given every $2 \mathrm{~h}$ in male and female sheep fetuses

\begin{tabular}{lccc}
\hline & $\begin{array}{c}\text { Females }(n=6) \\
\text { LH pulse } \\
\text { amplitude } \\
\left(\mathrm{ng} \mathrm{ml}^{-1}\right)\end{array}$ & $\begin{array}{c}\text { LH pulse } \\
\text { amplitude } \\
\left.(\mathrm{ng} \mathrm{ml})^{-1}\right)\end{array}$ & $\begin{array}{c}\text { Testosterone } \\
\text { response } \\
\left.(\mathrm{ng} \mathrm{ml})^{-1}\right)\end{array}$ \\
\hline 121 & $9.03 \pm 1.98^{\mathrm{a}}$ & $11.51 \pm 2.84^{\mathrm{a}}$ & $1.67 \pm 0.29^{\mathrm{a}}$ \\
(First GnRH pulse) & $3.07 \pm 1.28^{\mathrm{b}}$ & $2.05 \pm 0.25^{\mathrm{b}}$ & $2.31 \pm 1.15^{\mathrm{a}}$ \\
127 & $1.73 \pm 0.92^{\mathrm{b}}$ & $2.99 \pm 0.34^{\mathrm{b}}$ & $7.40 \pm 1.84^{\mathrm{b}}$ \\
134 & & & \\
\hline
\end{tabular}

Values (means \pm sem) with different superscripts within each column are significantly $(P<0,01$, ANOVA) different.

Table 2. FSH and immunoreactive inhibin concentrations in response to $500 \mathrm{ng}$ $\mathrm{GnRH}$ injections given every $2 \mathrm{~h}$ in male and female sheep fetuses

\begin{tabular}{crrrr}
\hline \multirow{2}{*}{ Day of Gestation } & \multicolumn{2}{c}{$\begin{array}{c}\text { Basal FSH (ng mi } \\
\text { Female }\end{array}$} & Male & \multicolumn{2}{c}{$\begin{array}{c}\text { Mean inhibin (ng ml } \\
\text { Female }\end{array}$} & Male \\
& & & & \\
121 Control & $6.53 \pm 0.81(7)^{\mathrm{a}}$ & $5.58 \pm 0.65(4)^{\mathrm{a}}$ & $0.28 \pm 0.07$ & $0.90 \pm 0.14$ \\
GnRH & $11.00 \pm 1.17(6)^{\mathrm{b}}$ & $8.14 \pm 0.43(7)^{\mathrm{a}}$ & $0.26 \pm 0.04$ & $0.79 \pm 0.18$ \\
127 Control & $5.47 \pm 0.89^{\mathrm{a}}$ & $4.63 \pm 1.65^{\mathrm{a}}$ & $0.36 \pm 0.04$ & $1.27 \pm 0.20$ \\
GnRH & $15.82 \pm 2.24^{\mathrm{bc}}$ & $13.40 \pm 1.52^{\mathrm{b}}$ & $0.29 \pm 0.06$ & $1.32 \pm 0.19$ \\
134 Control & $6.53 \pm 0.22^{\mathrm{a}}$ & $4.77 \pm 0.79^{\mathrm{a}}$ & $0.38 \pm 0.03$ & $1.56 \pm 0.20$ \\
GnRH & $20.87 \pm 0.96^{\mathrm{c}}$ & $14.69 \pm 0.82^{\mathrm{b}}$ & $0.30 \pm 0.02$ & $1.60 \pm 0.20$
\end{tabular}

Basal FSH values (mean \pm sem for the number of fetuses shown in parentheses) with different superscripts within each column are significantly $(P<0.01$. ANOVA) different. For immunoreactive inhibin there was a significant $(P<0.05$, ANOVA) increase in control and GnRH-treated male fetuses between day 121 and day 134. There were no changes in inhibin concentrations in female fetuses.

immunoreactivity in either the fetal testis or ovary. The expression of inhibin $\alpha$-subunit earlier in gestation in males than in females corresponds to the differences in immunoreactive inhibin measured in fetal plasma. However, the lack of $\beta A$ subunit gene expression suggests that biologically intact inhibin may not be synthesized by the fetus. This contention is supported by the fact that increasing concentrations of immunoreactive inhibin in males cannot prevent the rise in FSH secretion observed after long-term administration of GnRH to sheep fetuses (see Table 2). Conversely, the rise in FSH concentrations had no effects on plasma immunoreactive inhibin concentrations. This is in contrast to a recent report showing that pulsatile administration of FSH stimulates gonadal inhibin content in male and female fetuses (Albers et al., 1989). Unfortunately, plasma concentrations of inhibin were not measured, which makes it difficult to make a direct comparison with our own results. Further studies examining inhibin subunit gene expression in gonads collected after pulsed GnRH treatment will be necessary to resolve this.

\section{Functional Role of the Fetal Gonadotrophins}

In humans anencephalic fetuses frequently have male but hypoplastic external genitalia and hypoplastic undescended testes. Female anencephalic human fetuses bave hypoplastic ovaries with reduced numbers 


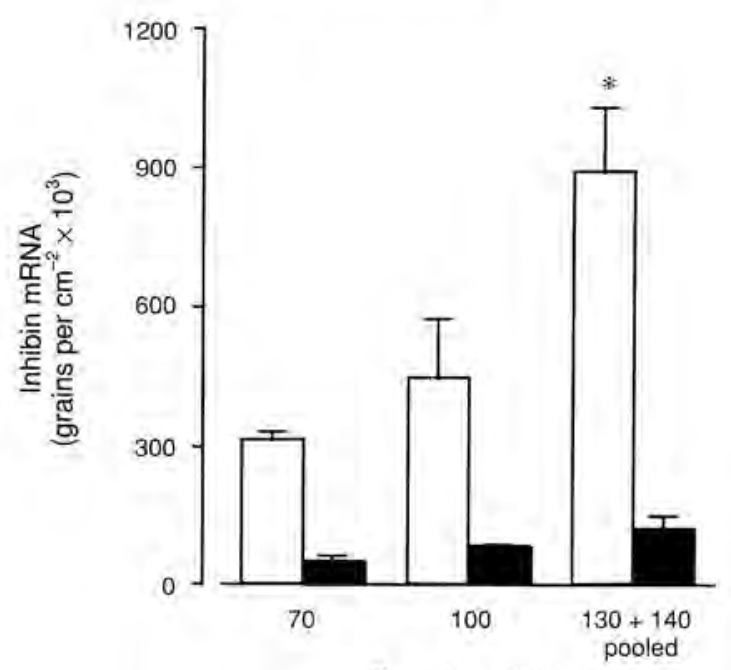

Day of gestation

Fig. 4. Expression of mRNA encoding inhibin $\alpha$-subunit (प) and inhibin $\beta A$-subunit ( $\mathbf{m}$ ) (grains $\mathrm{cm}^{-2}$ ) measured by in situ hybridization in testes of sheep fetuses. Each histogram represents the mean \pm SEM of four animals. $* P<0.05$ (ANOVA) compared with days 70 and 100.

of primordial and primary follicles (Grumbach and Kaplan, 1973; Kaplan et al., 1976). These early observations provide circumstantial evidence that fetal pituitary gonadotrophins are important for the normal maturation of the gonads during fetal development.

The sheep fetus treated with buserelin has proved a valuable model for determining more precisely the functional role of the fetal gonadotrophins during development. The advantage of the buserelin treatment is that it specifically inhibits gonadotrophin secretion without altering other pituitary hormones. Buserelin administration to male sheep fetuses during the second half of gestation results in a $40 \%$ reduction in the size of the testis at birth (Thomas et al., 1994a). This reduction in size is not associated with gross changes in morphology in the interstitial tissue or in the seminiferous cords. However, the total number of Sertoli cells per testis was found to be reduced by $45 \%$ in buserelin-treated ram lambs compared with controls (Fig. 5). In ewe lambs, buserelin treatment has no effect on ovarian mass or morphology; all ovaries were characterized by a cortical layer of primordial follicles, the number and diameter of which were not different from those of control animals. The observation that buserelin treatment affects male, but not female, gonadal development is in close agreement with earlier published data following pituitary ablation in sheep fetuses (Liggins and Kennedy, 1968) and suggests that ovarian development in the fetus is not critically dependent on exposure to gonadotrophins. This is perhaps not entirely surprising since it is well known that primordial follicles can mature to $2 \mathrm{~mm}$ in diameter in the absence of gonadotrophic support (Dufour et al., 1979; McNeilly and Fraser, 1987). However, this does not explain the ovarian abnormalities observed in anencephalic humans or the fact that pituitary ablation in rhesus monkey fetuses causes a reduction in ovarian mass and germ cells which is accompanied by an increase in the percentage of germ cells undergoing atresia (Gulyas et al., 1977). It is possible that ovarian development proceeded as normal under the influence of very low plasma concentrations of LH and FSH which persist in the circulation during buserelin treatment (Brooks and McNeilly, 1992). Alternatively, it may be that pituitary secretions other than the gonadotrophins are necessary for normal maturation of the developing ovaries. It is possible that growth hormone $(\mathrm{GH})$ might fulfil this role, as in adults $\mathrm{GH}$ is known to influence ovarian development via an interaction with the insulin-like growth factor system (see Webb et al., 1992), and circulating GH concentrations are very high during the period in fetal life when follicular maturation occurs (Gluckman ef al., 1981). However, a more plausible explanation is that there may be a critical window in gestation during which alterations to 


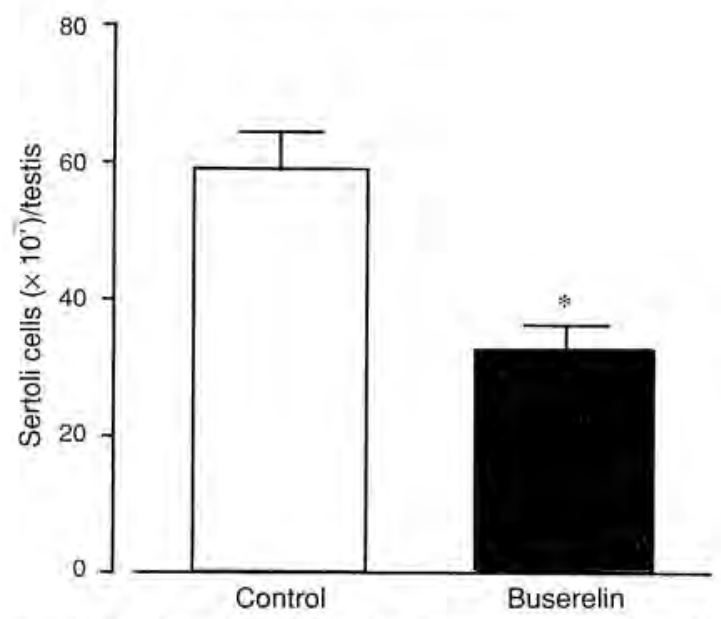

Fig. 5. Total number of Sertoli cells per testis in 2-day-old ram lambs treated with buserelin from day 70 of gestation. Values are means \pm Sem for three control and five buserelin-treated animals. "Significantly different from controls. (Reproduced from Thomas et al.; 1994a by permission of the Journal of Endocrinology Ltd.)

gonadotrophin secretion cause changes in gonadal development. In females, oogenesis is complete by day $50-60$ of gestation and follicle formation begins at about day 75 . Between day 75 and day 90 there is an $80 \%$ loss of germ cells, which is followed by progressive maturation of follicles to reach the preantral or early antral stage (Mauleon, 1978; McNatty et al., 1991). The gonadotrophic requirements. for each of these processes is unclear but our finding that buserelin has no effect on ovarian development after day 70 suggests that the critical window may occur before this time.

For testicular development the critical window may be longer and probably encompasses the entire time during which Sertoli cell replication can occur. In sheep this is from about day 40 of gestation (sex differentiation is complete by this time) up to about 8 weeks after birth. However, suppression of gonadotrophin secretion in male fetuses by buserelin treatment between day 70 and day 110 has no effect on testicular development, implying that the critical window for gonadotrophic support of testicular growth occurs at some time after day 110 of gestation (Brooks and McNeilly, 1992). Of further interest is whether these manipulations of gonadotrophin secretion in utero have permanent effects on gonadal development in adult life. We recently examined this by determining postnatal testicular development in fetuses that were treated with buserelin from day 75 of gestation until birth (Thomas. et al., 1995). At birth, the diameter of the testes in lambs treated with buserelin during the second half of gestation were significantly smaller than those of sham-operated controls. However, by 8-10 weeks after birth, testes size was the same as that of control animals and there were no significant differences between them. These data suggest that, after inhibition of gonadotrophin secretion during fetal development, the prepubertal testis can compensate during the first few weeks of postnatal life. However, by 28 weeks of age, after the animals had reached puberty, plasma testosterone concentrations were significantly lower in lambs that had been treated with buserelin during the second half of gestation than in controls. Thus we conclude that although testis growth was not permanently compromised by inhibition of gonadotrophin secretion during fetal life, there may be important functional aspects which remain altered well into adulthood (Thomas et al, 1995),

\section{Conclusions}

This review has described the normal ontogeny and regulation of some of the key components of the fetal hypothalamo-pituitary-gonadal axis. The pivotal role that $\mathrm{GnRH}$ plays in this maturational process 
is clearly illustrated by the fact that inhibition of GnRIH action by administration of buserelin to sheep fetuses blocks the characteristic rise in fetal gonadotrophins at mid-gestation and leads to retarded gonadal development in male fetuses. The mid-gestation peak of gonadotrophic activity is normally followed by a period of low plasma LH and FSH concentrations. These suppressed concentrations of gonadotrophins result from a complex, and as yet poorly understood, interaction between a maturing sex-steroid (gonadal or placental) negative feedback system and an increase in central nervous system factors. Whatever the mechanisms involved, $\mathrm{GnRH}$ again occupies a key position in these maturational processes. This is illustrated by the fact that pulsatile GnRH administration during late gestation, when gonadotrophic activity is suppressed, leads to pituitary gonadal activation with a resultant increase in LH, FSH and testosterone (in males).

The authors are extremely grateful to J. Sandow and W. von Rechenberg (Hoechst AG, Frankfurt) for the generous gift of buserelin implants and to the National Hormone and Pituitary Program, National Institute of Diabetes and Kidney diseases for the provision of many of the antibodies used in these studies. They also thank N. Anderson, J. Docherty, F. Gibson and M. Millar for their expert technical support.

\section{References}

Albers N, Bettendorf M, Hart CS, Kaplan SL and Grumbach MM (1989) Hormone ontogeny in the ovine fetus. XXIII. Pulsatile administration of follicle stimulating hormone stimulates inhibin production and decreases testosterone synthesis in the ovine fetal gonad Endocrinology 124 3089-3094

Albers $\mathrm{N}$, Bettendorf $\mathrm{M}$, Herrmann $\mathrm{H}_{t}$ Kaplan $\mathrm{S}$ and Grumbach MM (1993) Hormone ontogeny in the ovine fetus. XXVII. Pulsatile and copulsatile secretion of lutejnizing hormone, follicle stimulating homone, growth hormone, and prolactin in late gestation: a new method for the analysis of copulsatility Endocrinology 132 701-709

Alexander DP, Britton HG, Corker CS, Naftolin F and Nixon DA (1973) Plasma luteinizing hormone and oestrogen in foetal and maternal sheep Joumal of Endocrinology 56 331-332

Asa S, Kovacs K, Laszlo FA, Domokos I and Ezrin C (1986) Human fetal adenohypophysis: histological and immunocytochemical analysis Neuroendocrinology 43 308-316

Brooks AN and McNeilly AS (1992) Inhibitory effects of a luteinizing hormone-releasing hormone agonist implant on ovine fetal gonadotrophin secretion and pituitary sensitivity to luteinizing hormone-releasing hormone Journal of Reproduction and Fertility $\mathbf{9 6}$ 785-792

Brooks AN, Currie IS, Gibson F and Thomas GB (1992) Neuroendocrine regulation of sheep fetuses Journal of Reproduction and Ferfility Supplement 45 69-84

Caldani M, Antoine M, Batailler M and Duittoz A (1995) Ontogeny of the GnRH systems Journal of Reproduction and Fertility Supplement 49 147-162

Challis JRG and Brooks AN (1989) Maturation and activation of hypothalamic-pituitary-adrenal function in fetal sheep Endocrine Revietos 10 182-204

Challis JRG, Patrick JE, Cross J, Workewych J, Manchester E and Power S (1981) Short-term fluctuations in the concentrations of cortisol and progesterone in fetal plasma. maternal plasma and amniotic fluids from sheep during late pregnancy Canadian Journal of Physiology and Pharmacology 59 261-20̈7

Clark SJ, Ellis N, Styne DM, Gluckman PD, Kaplan SL and Grumbach MM (1984) Hormone ontogeny in the ovine fetus. XVII. Demonstration of pulsatile luteinizing hormone secretion by the fetal pituitary gland Endocrinology 115 $1774-1779$

Dufour JJ، Cahill LP and Mauleon P (1979) Short-and longterm effects of hypophysectomy and unilateral ovariectomy on ovarian follicular populations in sheep Joumal of Reproduetion and Fertility 57 301-309

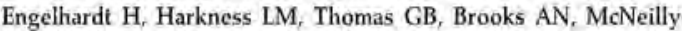
AS and Baird DT Expression of inhibin $\alpha$ - and $B A$ subunit mRNA and protein in the fetal sheep ovary throughout gestation Molecilar and Cellular Endocrinology (in press)

Foster DL, Roach JF, Karsch FJ, Norton HW, Cook B and Nalbandov AV (1972) Regulation of luteinizing hormone in the fetal and neonatal lamb. 1 LH concentrations in blood and pituitary Endocrinology $90102-111$

Gluckman PD, Grumbach MM and Kaplan SL (1981) The neuroendocrine regulation and function of growth hormone and prolactin in the mammalian fetus Endocrine Reviews $\mathbf{2}$ $363-395$

Gluckman PD, Marti-Henneberg C, Kaplan SL and Grumbach MM (1983) Hormone ontogeny in the ovine fetus; XIV, The effect of 173 -estradiol infusion on fetal plasma gonadotrophins and prolactin and the maturation of sex steroid dependent negative feedback Endocrinology $1121618-$ 1623

Gorski RA (1985) Sexual differentiation of the brain: possible mechanisms and implication Canadian Joumal of Physiology and Pharmacology 63 577-594

Grumbach MM and Kaplan SL (1973) Ontogenesis of growth homone, insulin, prolactin and gonadotrophin secretion in the human fetus. In Fetal and Neonatal Physiology (Sir Joseph Barcroft Centenary Symposium) pp $462-487$ Eds KS Comline, KW Cross, GS Dawes and PW Nathanielsz. Cambridge University Press, Cambridge

Gulyas BJ, Hodgen GD, Tullner WW and Ross GT (1977) Effects of fetal or maternal hypophysectomy on endocrine organs and body weight in infant rhesus monkeys (Macata mulatta): with particular emphasis on oogenesis Biology of Reproduction 16 216-227

Hadj L, Toumi M, Taragnat C and Durand P (1993) Heterogeneity in the storage of gonadotrophins in the ovine fetus and evidence for luteinizing hormone-follide-stimulating 
hormone cells in the fetal pituitary Biology of Reproduction $48 \quad 1239-1245$

Kaplan SL, Grumbach MM and Aubert ML (1976) The ontogenesis of pituitary hormones and hypothalamic factors in the human fetus: maturation of central nervous system regulation of anterior pituitary function Recent Progress in Hormone Research 32 1ó1-243

Levidiotis M, Wintour EM, McKinley MJ and Oldfield BJ (1989) Hypothalamic-hypophyseal vascular connections in the fetal sheep Neuroendocrinology $4947-50$

Liggins GC and Kennedy PC (1968) Effects of electrocoagulation of the foetal lamb hypophysis on growth and development Joumal of Endocrinology 40 371-381

McLeod BJ and McNeilly AS (1987) Suppression of plasma FSH concentrations with bovine follicular fluid blocks ovulation in GnRH-treated seasonally anoestrous ewes Joumal of Reproduction and Fertility 81 187-194

McNatty KP. Smith P, Hudson DA, Heath DA, Lun S and O WS (1991) Follicular development and steriodogenesis. In Local Regulation of Ovarian Function Ed. EK Fernstion. University of Lund, Lund

McNeilly AS and Fraser HM (1987) Effect of GnRH agonistinduced suppression of LH and FSH on follicle growth and corpus luteum function in the ewe Journal of Endocrinology $115 \quad 273-282$

Martin GB (1984) Factors affecting the secretion of luteinizing hormone in the ewe Biological Reviews 59 1-87

Matwijiw I and Faiman C (I987) Control of gonadotrophin secretion in the ovine fetus the effects of a specific gonadotrophin-releasing hormone antagonist on pulsatile luteinizing hormone secretion Endocrinology 121 $347-351$

Matwijiw 1 and Faiman C (1989) Control of gonadotrophin secretion in the ovine fetus. II. A sex difference in pulsatile luteinizing hormone secretion after castration Endocrinology $1241352-1358$

Matwijiw 1 and Faiman C (1991) Control of gonadotrophin secretion in the ovine fetus. IV. Male specific entrairument of the hypothalamic control of luteinizing hormone secretion by testosterone in the female ovine fetus Endocrinology 129 1447-1451

Matwijiw I. Thliveris JA and Faiman C (1989) Hypothalamopituitary portal development in the ovine fetus Biology of Reproduction 40 1127-1130

Mauleon P (1978) Ovarian development in young mammals. In Conirol of Ovulation pp I4I-158 Eds DB Crighton, NB Haynes, GR Foxcroft and GE Lamming. Butterworths, London
Mesiano S, Hart CS, Heyer BW, Kaplan SL and Grumbach MM (1991) Hormone ontogeny in the ovine fetus XXVI. A sex difference in the effect of castration on the hypothalamicpituitary gonadotrophin unit in the ovine fetus Endocrinology 129 3073-3079

Mueller PL, Sklar CA, Gluckman PD, Kaplan SL and Grumbach MM (1981) Hormone ontogeny in the ovine fetus. IX. Luteinizing hormone and follicle-stimulating hormone response to luteinizing homone-releasing factor in mid- and late gestation and in the neonate Endocrinology 108 881-886

Phillips DJ, Smith PR, Heath DA, Condell LA and McNatty KP (1992) Bioactive and immunoreactive FSH and immunoreactive inhibin concentrations in the ovine fetus Journal of Endocrinologiy 134 287-295

Simmons DM, Voss JW, Ingraham HA, Holloway JM, Broide RS, Rosenfeld MG and Swanson IW (1990) Pituitary cell phenotypes involve cell-specific Pit-1 mRNA translation and synergistic interactions with other classes of transcription factors Genes and Development 4 695-711

Sklar CA, Mueller PL, Gluckman PD, Kaplan SL, Rudolph AM and Grumbach MM (1981) Hormone ontogeny in the ovine fetus. VII. Circulating luteinizing hormone and follicle stimulating hormone in mid-and late gestation Endocrinology 108 874-880

Thomas GB, McNeilly AS and Brooks AN (1993) Development of gonadotrophs and thyrotrophs in the female foetal sheep pituitary: immunocytochemical localization studies Journal of Neuroendocrinology 5 157-16́1

Thomas GB, McNeilly AS, Gibson F and Brooks AN (1994a) Effects of pituitary-gonadal suppression with a gonadotrophin-releasing hormone agonist on fetal gonadotrophin sećetion, fetal gonadal development and maternal steroid secretion in the sheep Jountal of Endocrinology 141 $317-324$

Thomas GB, Engelhardt H, Baird DT, McNeilly AS and Brooks AN (1994b) Expression of mRNA and immunocytochemical localization of inhibin subunits in the sheep fetal testis and ovary Journal of Reproduction and Fertility. Abstract Series 13 Abstrack 105

Thomas GB, McNeilly AS and Brooks AN (1995) Effects of suppression of pituitary-testicular function during fetal life with a $\mathrm{GnRH}$ agonist on reproductive development in ram lambs during the first 28 weeks of life Journal of Reproduction and Fertility Supplement 49 533-537

Webb R, Gong JG, Law AS and Rusbridge SM (1992) Control of ovarian function in cattle Journal of Reproduction and Fertility Supplement 45 I4 I-156 